\title{
INTEGRATION OF FETAL MID THIGH SOFT TISSUE THICKNESS IN ULTRASOUND BIRTH WEIGHT ESTIMATION FORMULA INCREASES THE ACCURACY OF FETAL WEIGHT ESTIMATION NEAR TERM
}

\author{
SHRIPAD HEBBAR*, SUKRITI MALAVIYA, SUNANDA BHARATNUR \\ Department of Obstetrics and Gynaecology, Kasturba Medical College, Manipal Academy of Higher Education, Manipal - 576 104, \\ Karnataka, India. Email: drshripadhebbar@yahoo.co.in
}

Received: 20 November 2017, Revised and Accepted: 29 December 2017

ABSTRACT

Objective: The objective of the study was to find whether incorporation of MTSTT in fetal weight estimation formulae which are traditionally based on biparietal diameter (BPD), head circumference (HC), abdominal circumference (AC), and femur length (FL) improves birth weight (BW) estimation.

Methods: In a prospective observational study, MTSTT was measured within 1 week of delivery in 100 women with term singleton pregnancy along with other standard biometric parameters, i.e. BPD, HC, AC and FL, and MTSTT. Multiple regression analysis was carried out using PHOEBE regression software using different combinations of biometric variables to find out the best fit model of fetal weight estimation. The predicted BW was compared with actual neonatal BW soon after delivery and regression coefficients $\left(\mathrm{R}^{2}\right)$ were determined for each of prediction models for comparing the accuracies.

Results: Mean gestational age at delivery was 38.4 \pm 1.08 weeks and the BW of neonates varied between $2.18 \mathrm{~kg}$ and $4.38 \mathrm{~kg}$ (mean \pm standard deviation: $3.07 \pm 0.43 \mathrm{~kg})$. By adding MTSTT to BPD, HC, AC, and FL, we obtained the formula Log $10(\mathrm{BW})=-0.14783+0.00725 * \mathrm{BPD}+0.00043 * \mathrm{HC}$ $+0.00436 * \mathrm{AC}+0.01942 * \mathrm{FL}+0.16299 *$ MTSTT, which had a very good Pearson regression coefficient $\left(\left(\mathrm{r}^{2:} 0.89 \mathrm{p}<0.001\right)\right.$ compared to conventional models based on standard fetal biometry. All prediction models had better strength of correlation when combined with MTSTT (p<0.001). The routine four parameter formula could identify $45 \%$ and $80 \%$ of fetuses within $5 \%$ and $10 \%$ weight range; pick up rate was further increased to $61 \%$ and $95 \%$ by addition of MTSTT.

Conclusion: It is evident that addition of MTSTT to other biometric variables in models of fetal weight estimation improves neonatal BW prediction $\left(r^{2}=0.89\right)$

Keywords: Fetal weight, Mid-thigh soft-tissue thickness, Ultrasonography.

(C) 2018 The Authors. Published by Innovare Academic Sciences Pvt Ltd. This is an open access article under the CC BY license (http://creativecommons. org/licenses/by/4.0/) DOI: http://dx.doi.org/10.22159/ajpcr.2018.v11i4.23776

\section{INTRODUCTION}

In modern obstetrics appropriate knowledge of fetal weight before planning mode of delivery is of utmost importance and it is wellknown that allowing vaginal delivery in undiagnosed fetopelvic proportion may be associated with higher incidence of maternal and neonatal morbidity such as reproductive trauma and birth injuries due to problems associated with the second stages such as instrumental delivery, shoulder dystocia and birth trauma leading significant and long-term problems both in mother and the neonate [1-3].

In low resource settings, the only way to determine approximate before birth is clinical estimation using different formulae based on measurements of symphysis fundal height $[4,5]$, abdominal girth [6], and station of fetal head [7]. However, these methods are associated with estimation errors somewhere between 10 and 20\% [8,9], of the actual birth weight (BW), which can be either underestimation or overestimation. Underestimation of the potentially large baby is associated with labor abnormalities such as prolonged active phase, protracted decent of the presenting part, and shoulder dystocia, whereas overestimation of the small-sized baby may lead to iatrogenic premature delivery and neonatal problems due to low BW $[10,11]$. This suggests that accurate BW estimation is necessary to limit the complications associated with both undersized and oversized fetuses.
Since the advent of ultrasound in obstetrics by Prof. Ian Donald [12], the fetal weight estimation has been revolutionized, and ample of information is available on this aspect of ultrasound practice [13].

Now it is possible to measure various fetal biometric parameters such as biparietal diameter (BPD), head circumference (HC), abdominal circumference (AC), and femur length (FL) and multiple formulae have been derived by regression analysis with various accuracies both in low BW and macrosomic babies [14-16]. These biometric measurements are based on linear or planar measurements of in utero fetal sections, and definite guidelines have been laid down about measurement techniques [17]. Ideally, a BW estimation formula should have least systematic and random errors with at least $90 \%$ correlation. However, due to biological, ethical, regional and many other unknown factors, at present, it appears that ultrasound formulae using conventional biometric parameters have reached their diagnostic limits. This indicates that there is a need for additional parameters to improve accuracy BW prediction models $[18,19]$.

The value of mid-arm circumference is well known in neonatology to screen for low BW babies [20]. This can be extrapolated to intrauterine measurement of body fat areas such as mid-thigh mass, abdominal fat mass, subscapular fat, and cheek-to-cheek diameter [21,22]. Studies have proved that extent of subcutaneous fat distribution also influences the 
fetal weight and incorporating fat thickness in ultrasound formulae greatly increases the accuracy of antenatal determination of expected BW [23-26].

Among soft tissue dimensions, measurement of mid-thigh soft-tissue thickness (MTSTT) is gaining considerable attention among researchers and but there are very few Indian studies in this context [27-29]. The present study examines the role of adding MTSTT to conventional biometric parameters in regression equations and whether this can improvise the ultrasound-based fetal BW prediction models.

\section{METHODS}

This prospective cross-sectional study was conducted in the Department of Obstetrics and Gynaecology from a tertiary referral hospital between August 2013 and August 2015. The study was approved by Institutional Ethical Committee, and all the patients gave informed consent. The study population included singleton term patient with a scan done within a week of delivery between 37 and 40 weeks. Pregnancies with multiple gestations, fetuses with congenital anomalies were excluded from the study. Pregnancy complications such as preeclampsia and gestational diabetes mellitus were not exclusion criteria unless congenital anomalies in the fetus. Sample size estimation was done using the model;

$\mathrm{N}=50+8 \mathrm{~K}$,

Where in $\mathrm{N}$ is the number of patients required and $\mathrm{K}$ is the number of independent variables.

According to the above formulae, the sample size was calculated as a minimum of 98 . Our sample size of 100 was thus more than enough to derive statistically significant results.

The sonographic examination was performed by the first author using ultrasonography Machine with a 3.5 MHz probe (Philips HD11XE) and). BPD, HC, AC, and FL was assessed by standard methods [30]. Using sliding and rotatory movements the entire length of the femur was captured along with thigh outer borders making sure that the image occupied at least $75 \%$ of the screen (Figs. 1 and 2). We defined MTSTT as thickness of the vastus lateralis muscle including adipose tissue right up to skin margin at the level of mid femur. Both thicknesses (superior and inferior to mid femur) were obtained and average of these measurements was considered for calculation of MTSTT. Actual BW also was measured immediately after birth.

\section{Statistical analysis}

To find the best fit model for predicting BW, different combinations of ultrasound biometric parameters were analyzed by PHOEBE regression software. We used $\mathrm{cm}$ as a unit for these biometric variables, and BW was expressed in kilogram (kg). As BW distribution did not follow normal distribution, we used various transformations to fit the BW distribution curve to near normality using Kolmogorov Smirnov test. Log transformation of BW was found to fit normality rules, and hence Log 10 (BW) was used for prediction of BW. Regression coefficients $\left(\mathrm{R}^{2}\right)$ were determined for each of prediction models for comparing the accuracies.

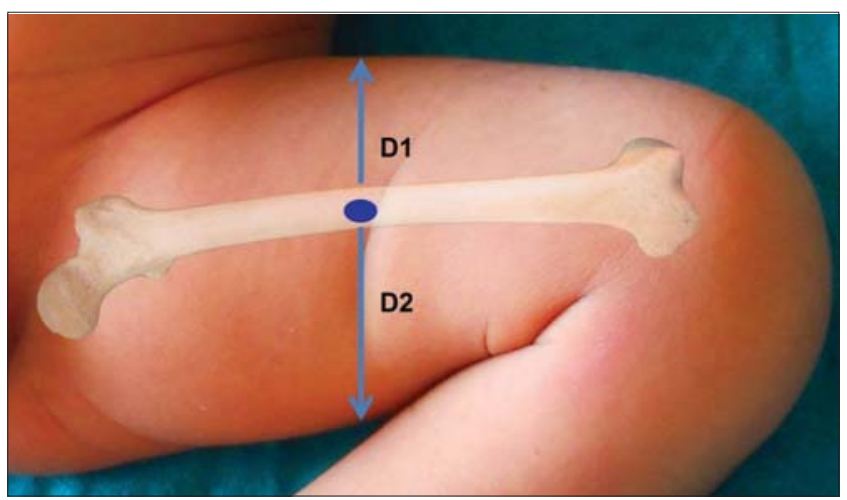

Fig. 1: Principle of measurement

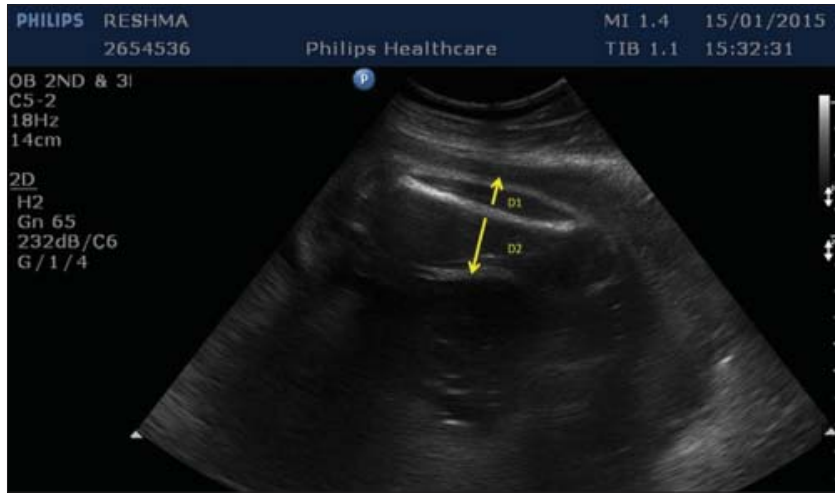

Fig. 2: Actual measurement

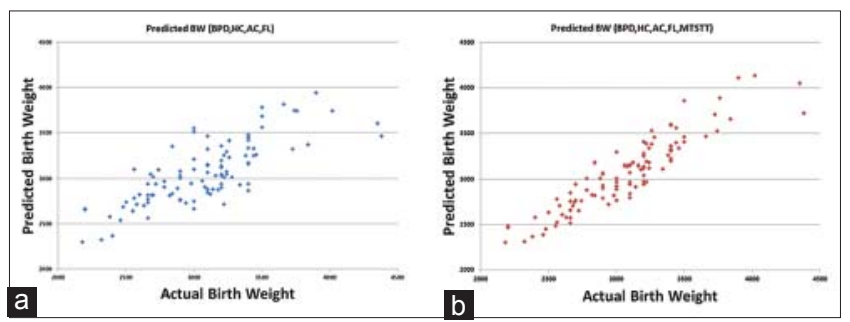

Fig. 3: ( $a$ and b) Scattered diagrams for birth prediction model accuracies using four standard biometric parameters $\left(R^{2:} 0.65\right.$,

$<0.001$ ) as in figure on the left side. Right side figure shows

addition mid-thigh soft-tissue thickness to four standard

parameters further improves neonatal birth weight assessment (R: 0.89, p<0.001)

Table 1: Demographic and obstetric characteristics of the study population $(n=100)$

\begin{tabular}{ll}
\hline Parameters & Observation \\
\hline Maternal age (mean \pm SD) & $28.4 \pm 4.025$ \\
Primipara & 62 \\
Multipara & 38 \\
Gestational age (mean \pm SD) & $38.4 \pm 1.08$ \\
*Fetal sex & \\
Male & 46 \\
Female & 54 \\
BW & \\
Min & 2180 \\
Max & 4380 \\
Mean $\pm S D$ & $3071.45 \pm 430.019$ \\
\hline
\end{tabular}

*Gender checked after delivery. SD: Standard deviation, BW: Birth weight

Table 2: Descriptive statistics of ultrasonic variables (in $\mathrm{cm}$ ) in term pregnancy $(n=100)$

\begin{tabular}{llll}
\hline Parameter & Mean \pm SD & Minimum & Maximum \\
\hline BPD & $9.2155 \pm 0.3984$ & 8.31 & 10.2 \\
HC & $32.974 \pm 1.3412$ & 28.8 & 36.1 \\
AC & $33.055 \pm 1.9194$ & 27.9 & 38.3 \\
FL & $7.2664 \pm 0.37477$ & 6.1 & 8.4 \\
MTSTT & $1.6224 \pm 0.26849$ & 1.08 & 2.28 \\
\hline
\end{tabular}

BPD: Biparietal diameter, HC: Head circumference, AC: Abdominal

circumference, FL: Femur length, MTSTT: Mid-thigh soft-tissue thickness, SD: Standard deviation

\section{RESULTS}

Table 1 summarizes demographic characteristics of the patients studied. Mean \pm standard deviation (SD) for mothers' age was $28.4 \pm 4.025$ years. Mean gestational age at delivery was found to be $38.4 \pm 1.08$ weeks and 
Table 3: Descriptive statistic of ultrasonic variables in term pregnancy $(n=100)$

\begin{tabular}{ll}
\hline Variables & Predictive formulae \\
\hline BPD, AC & Log10 $(\mathrm{BW})=-0.40925+0.02251 * \mathrm{BPD}+0.02072 * \mathrm{AC}$ \\
$\mathrm{BPD}, \mathrm{AC}, \mathrm{MTSTT}$ & $\log 10(\mathrm{BW})=-0.05752+0.01037 * \mathrm{BPD}+0.00492 * \mathrm{AC}+0.17401 * \mathrm{MTSTT}$ \\
$\mathrm{BPD}, \mathrm{FL}$ & $\log 10(\mathrm{BW})=-0.53585+0.04803 * \mathrm{BPD}+0.07931 * \mathrm{FL}$ \\
$\mathrm{BPD}, \mathrm{FL}, \mathrm{MTSTT}$ & $\log 10(\mathrm{BW})=-0.09193+0.01367 * \mathrm{BPD}+0.02162 * \mathrm{FL}+0.17988^{*} \mathrm{MTSTT}$ \\
$\mathrm{BPD}, \mathrm{AC}, \mathrm{FL}$ & $\log 10(\mathrm{BW})=-0.57899+0.0147 * \mathrm{BPD}+0.01678 * \mathrm{AC}+0.0512 * \mathrm{FL}$ \\
$\mathrm{BPD}, \mathrm{AC}, \mathrm{FL}, \mathrm{MTSTT}$ & $\log 10(\mathrm{BW})=-0.14548+0.00815 * \mathrm{BPD}+0.00442 * \mathrm{AC}+0.01969 * \mathrm{FL}+0.16279 * \mathrm{MTSTT}$ \\
$\mathrm{BPD}, \mathrm{HC}, \mathrm{AC}, \mathrm{FL}$ & $\log 10(\mathrm{BW})=-0.55881+0.02089 * \mathrm{BPD}-0.003 * \mathrm{HC}+0.01709 * \mathrm{AC}+0.0528 * \mathrm{FL}$ \\
$\mathrm{BPD}, \mathrm{HC}, \mathrm{AC}, \mathrm{FL}, \mathrm{MTSTT}$ & $\log 10(\mathrm{BW})=-0.14783+0.00725 * \mathrm{BPD}+0.00043 * \mathrm{HC}+0.00436 * \mathrm{AC}+0.01942 * \mathrm{FL}+0.16299 * \mathrm{MTSTT}$ \\
\hline
\end{tabular}

BPD: Biparietal diameter, HC: Head circumference, AC: Abdominal circumference, FL: Femur length, MTSTT: Mid-thigh soft-tissue thickness, BW: Birth weight

majorities were primigravida. The BW of neonates varied between $2.18 \mathrm{Kg}$ and $4.38 \mathrm{Kg}$ (mean \pm SD: $3.07 \pm 0.43 \mathrm{~kg}$ ).

Descriptive statistics of five major ultrasound biometric parameters are shown in Table 2. All measurements are given in $\mathrm{cm}$. BPD, HC, AC, and FL measurements are approximately same as term (37-40 weeks) measurements. Mean \pm SD for the new parameter (MTSTT) was $1.62 \pm 0.26 \mathrm{~cm}$.

Predictive BW formulas derived by PHOBE linear regression software are illustrated in Table 3. It can be seen that addition of MTSTT to any combinations of standard biometric parameters improve the correlation statistics significantly $(p=0.001)$ and when MTSTT measurement is added to all four major parameters (BPD, HC, AC, and FL) the maximum $R^{2}$ values (0.89) can be achieved. The conventional four parameter formula could identify $45 \%$ and $80 \%$ of fetuses within $5 \%$ and $10 \%$ weight range; pick up rate was further increased to $61 \%$ and $95 \%$ by addition of MTSTT.

Fig. 3a and $\mathrm{b}$ are the scattered diagrams showing a correlation between actual BW and predicted BW on $\mathrm{x}$ - and $\mathrm{y}$-axis. It can be understood that by adding MTSTT the dispersion of the actual and predicted BW can be reduced and thereby demonstrating their closeness.

\section{DISCUSSION}

The importance of fetal weight estimation in planning the optimal route of delivery in obstetric care cannot be underestimated. The conventional formulae adopted by modern ultrasound machines still are based on the Hadlock formula which was invented in the early 90s [14,17]. Even with careful and repeated measurements, ultrasonically estimated BW can differ from actual BW by $10 \%-15 \%$. This is because neonatal body weight is influenced by soft tissue distribution and by incorporating those into traditional formulae may decrease these errors [22].

Many studies have focused on improvisation of BW prediction models by adding subcutaneous fat thickness. Foromouzmehr et al. showed a linear relation between abdominal fat and BW in babies of all weight ranges and this association was present even when the ultrasound estimation of weight was performed within 11 days of delivery [31]. Several studies have focused on the role of abdominal fat thickness in predicting macrosomic babies in pregnancies complicated by gestational diabetes [32,33]. Higgins et al. found that anterior abdominal wall thickness in large babies was significantly more compared to normal babies [34]. They opined that if this thickness is $>5.6 \mathrm{~mm}$, along with $\mathrm{AC}>90^{\text {th }}$ centile, the obstetrician should be alerted as the baby may have macrosomia.

However, these studies have focused only on fat distribution, but even the muscle mass will contribute to the overall weight of the baby. Extensive studies done by Bernstein and coworkers have shown that both lean (muscle) mass, as well as a fat mass, are related to fetal growth right from the beginning of the second trimester and exhibit a unique pattern especially in diabetic pregnancies $[35,36]$. It was the novel idea of Scioscia et al. (2008) who proposed that femoral soft tissue thickness can be used as a potential marker of BW [37]. They also proved that MTSTT can replace AC measurements whenever there is a technical difficulty to obtain correct plane for fetal abdominal transverse section [38]. They further extended their study in the prediction of macrosomia and opined that only linear measurements (including femur soft tissue thickness) are good enough to estimate large BW [28]. An Iranian study showed adding mid-thigh tissue parameters to conventional biometric formula improves the accuracy of BW prediction $\left(\mathrm{R}^{2}=0.77\right)$ [27]. An Egyptian study too found association between fetal thigh measurements and actual BW $\left(\right.$ MTSTT- $^{2}=0.656$, $\left.\left.\mathrm{p}<0.001), \quad F L-R^{2}=0.573, \quad p<0.001\right), \quad B P D-R^{2}=0.250, \quad p<0.001\right)$, and $A C-R^{2}=0.310, p<0.001$ ) [29].

Although it appears that MTSTT can be effective replacement for difficult AC measurements, there may be situations where dimensional assessment fetal thigh may be technically impossible as in cases of breech presentations. However, this particular presentation contributes for only $3 \%$ of fetal presentations, and still MTSTT can be used in rest of $97 \%$ of presentations [27]. The value of MTSTT in predicting fetal weight in preterm fetuses, multifetal gestation, hypertensive disorders of pregnancy [39], and thyroid disorders [40] has still to be explored. MTSTT can be useful in the evaluation of intrauterine growth restriction along with Doppler study and umbilical cord morphology to assess the fetal weight and neonatal outcome [41,42].

\section{CONCLUSION}

MTSTT being a linear measurement is easy to obtain, simple and accurate and can be added to standard biometric parameters to improve fetal weight estimation by ultrasound at term before delivery. These findings suggest that establishment of gestational age-specific MTSTT ranges and incorporating them into intrauterine growth charts at sequential ultrasound scans may help in identifying the disorders of fetal growth.

\section{REFERENCES}

1. Murguía-González A, Hernández-Herrera RJ, Nava-Bermea M. Risk factors of birth obstetric trauma. Ginecol Obstet Mex 2013;81:297-303.

2. Kjaergaard H, Olsen J, Ottesen B, Dykes AK. Incidence and outcomes of dystocia in the active phase of labor in term nulliparous women with spontaneous labor onset. Acta Obstet Gynecol Scand 2009;88:402-7.

3. Caughey AB, Musci TJ. Complications of term pregnancies beyond 37 weeks of gestation. Obstet Gynecol 2004;103:57-62.

4. Curti A, Zanello M, De Maggio I, Moro E, Simonazzi G, Rizzo N, et al. Multivariable evaluation of term birth weight: A comparison between ultrasound biometry and symphysis-fundal height. J Matern Fetal Neonatal Med 2014;27:1328-32.

5. Indraccolo U, Chiocci L, Rosenberg P, Nappi L, Greco P. Usefulness of symphysis-fundal height in predicting fetal weight in healthy term pregnant women. Clin Exp Obstet Gynecol 2008;35:205-7.

6. Mortazavi F, Akaberi A. Estimation of birth weight by measurement of fundal height and abdominal girth in parturients at term. East Mediterr Health J 2010;16:553-7.

7. Belete W, Gaym A. Clinical estimation of fetal weight in low resource settings: Comparison of Johnson's formula and the palpation method. Ethiop Med J 2008;46:37-46.

8. Chauhan SP, Hendrix NW, Magann EF, Morrison JC, Kenney SP, Devoe LD, et al. Limitations of clinical and sonographic estimates of birth weight: Experience with 1034 parturients. Obstet Gynecol 1998;91:72-7.

9. Peregrine E, O’Brien P, Jauniaux E. Clinical and ultrasound estimation 
of birth weight prior to induction of labor at term. Ultrasound Obstet Gynecol 2007;29:304-9.

10. Mehdizadeh A, Alaghehbandan R, Horsan H. Comparison of clinical versus ultrasound estimation of fetal weight. Am J Perinatol 2000;17:233-6.

11. Shittu AS, Kuti O, Orji EO, Makinde NO, Ogunniy SO, Ayoola OO, et al. Clinical versus sonographic estimation of foetal weight in southwest Nigeria. J Health Popul Nutr 2007;25:14-23.

12. Campbell S. A short history of sonography in obstetrics and gynaecology. Facts Views Vis Obgyn 2013;5:213-29.

13. Wu M, Shao G, Zhang F, Ruan Z, Xu P, Ding H. Estimation of fetal weight by ultrasonic examination. Int J Clin Exp Med 2015;8:540-5.

14. Hadlock FP, Harrist RB, Sherman RS, Deter RL, Park SK. Estimation of fetal weight with the use of head, body, and femur measurements. Am J Obstet Gynecol 1985;150:333-7.

15. Dudley NJ. A systematic review of the ultrasound estimation of fetal weight. Ultrasound Obstet Gynecol 2005;25:80-9.

16. Hebbar S. Critical evaluation of various methods of estimating fetal weight by ultrasound. J Obstet Gynecol Ind 2003;53:336-9.

17. Hadlock FP, Harrist RB, Martinez-Poyer J. In utero analysis of fetal growth: A sonographic weight standard. Radiology 1991;181:129-33.

18. Kehl S, Schmidt U, Spaich S, Schild RL, Sütterlin M, Siemer J. What are the limits of accuracy in fetal weight estimation with conventional biometry in two-dimensional ultrasound? A novel postpartum study. Ultrasound Obstet Gynecol 2012;39:543-8.

19. Kumarasiri S, Wanigasekara R, Wahalawatta L, Jayasinghe L, Padeniya T, Dias T, et al. Accuracy of ultrasound estimated fetal weight formulae to predict actual birth weight after 34 weeks: Prospective validation study. Ceylon Med J 2013;58:116-21.

20. Cattermole GN, Leung PY, Mak PS, Graham CA, Rainer TH. Mid-arm circumference can be used to estimate children's weights. Resuscitation 2010;81:1105-10.

21. Chen L, Wu JJ, Chen XH, Cao L, Wu Y, Zhu LJ, et al. Measurement of fetal abdominal and subscapular subcutaneous tissue thickness during pregnancy to predict macrosomia: A pilot study. PLoS One 2014;9:e93077.

22. Lee W, Balasubramaniam M, Deter RL, Hassan SS, Gotsch F, Kusanovic JP, et al. Fetal growth parameters and birth weight: Their relationship to neonatal body composition. Ultrasound Obstet Gynecol 2009;33:441-6.

23. Valensise H, Larciprete G, Arduini D, Lorenzo AD. The fetal body compartments and their detection during pregnancy. A review. Acta Diabet 2003;40:79-82.

24. Foromouzmehr A, Shahrokh A, Molaei M. Estimation of birth weight using sonographically measured fetal abdominal subcutaneous tissue thickness. Iran J Radiol 2004;2:47-9.

25. Bhat RG, Nathan A, R A, Vasudeva A, Adiga P, Bhat PV, et al. Correlation of fetal abdominal subcutaneous tissue thickness by ultrasound to predict birth weight. J Clin Diagn Res 2014;8:OC09-11.

26. O'Connor C, Farah N, O'Higgins A, Segurado R, Fitzpatrick C, Turner MJ, et al. Longitudinal measurement of fetal thigh soft tissue parameters and its role in the prediction of birth weight. Prenat Diagn 2013;33:945-51.
27. Kalantari M, Negahdari A, Roknsharifi S, Qorbani M. A new formula for estimating fetal weight: The impression of biparietal diameter, abdominal circumference, mid-thigh soft tissue thickness and femoral length on birth weight. Iran J Reprod Med 2013;11:933-8.

28. Scioscia M, Stepniewska A, Trivella G, De Mitri P, Bettocchi S. Estimation of birth weight by measurement of fetal thigh soft-tissue thickness improves the detection of macrosomic fetuses. Acta Obstet Gynecol Scand 2014;93:1325-8.

29. Abuelghar W, Khairy A, El Bishry G, Ellaithy M, Abd-Elhamid T. Fetal mid-thigh soft-tissue thickness: A novel method for fetal weight estimation. Arch Gynecol Obstet 2014;290:1101-8.

30. McGahan JP, Goldberg BB. Diagnostic Ultrasound. $2^{\text {nd }}$ Ed. New York, London: Elsevier; 2008.

31. Shahrokh FA, Molaei M. Estimation of birth weight using sonographically measured fetal abdominal subcutaneous tissue thickness. Iran J Radiol 2004;2:47-9.

32. Parretti E, Carignani L, Cioni R, Bartoli E, Borri $\mathrm{P}$, La Torre $\mathrm{P}$, et al. Sonographic evaluation of fetal growth and body composition in women with different degrees of normal glucose metabolism. Diabetes Care 2003;26:2741-8.

33. Bethune M, Bell R. Evaluation of the measurement of the fetal fat layer, intraventricular septum and abdominal circumference percentile in the prediction of macrosomia in pregnancies affected by gestational diabetes. Ultrasound Obstet Gynecol 2003;22:586-90.

34. Higgins MF, Russell NM, Mulcahy CH, Coffey M, Foley ME, Mcauliffe FM. Fetal anterior abdominal wall thickness in diabetic pregnancy. Eur J Obstet Gynecol Reprod Biol 2008;140:43-7.

35. Bernstein IM, Goran MI, Amini SB, Catalano PM. Differential growth of fetal tissues during the second half of pregnancy. Am J Obstet Gynecol 1997; 176:28-32.

36. Bernstein IM, Catalano PM. Ultrasonographic estimation of fetal body composition for children of diabetic mothers. Invest Radiol 1991;26:722-6.

37. Scioscia M, Scioscia F, Vimercati A, Caradonna F, Maiorano A, Panella E, et al. Femoral soft tissuethickness as potential parameter for ultrasound estimation of fetal weight. Ultrasound Obstet Gynecol 2006;28:468.

38. Scioscia M, Scioscia F, Vimercati A, Caradonna F, Nardelli C, Pinto LR, et al. Estimation of fetal weight by measurement of fetal thigh softtissue thickness in the late third trimester. Ultrasound Obstet Gynecol 2008;31:314-20.

39. Velusamy S. Comparison of treatment outcome of antihypertensive drugs in the management of pregnancy-induced hypertension. Int $\mathrm{J}$ Pharm Pharm Sci 2017;9:287-9.

40. Hebbar S, Kumar S, Amin S, Doizode S. Subclinical hypothyroidism in pregnancy; Is there a need for pharmacological intervention? Int $\mathrm{J}$ Pharm Pharm Sci 2017;9:186-91.

41. Kiran K, Krishnananda N, Pratap K, Ranjan S, Jyothi, Leslie E, et al. Altered arterial Doppler flow pattern and perinatal outcome in intrauterine growth restriction. Asian J Pharm Clin Res 2017;10:425-8.

42. Susmita S, Shankar BS, Prafulla K. Evaluation of fetal weight sonographically using area of Wharton's jelly and morphology of umbilical cord. Asian J Pharm Clin Res 2017;10:253-8. 